\title{
Estratégias técnico-pedagógicas como facilitador cognitivo: uma experiência com alunos surdos
}

\author{
Rafael P. Granada ${ }^{1}$, Regina Barwaldt ${ }^{1}$, Nara Z. Gentil ${ }^{1}$ \\ ${ }^{1}$ Centro de Ciências Computacionais - Universidade Federal do Rio Grande (FURG) \\ 96.203-900 - Rio Grande - RS - Brasil \\ \{rafaelgranada, reginabarwaldt\}@furg.br, narazerwes@yahoo.com.br.
}

\begin{abstract}
This work aims to develop a computational glossary of signals with the main reserved words of the software SuperLOGO and Lego Mindstorms NXT as a stimulus to the logical reasoning in deaf people. The work was carried out in a Bilingual High School with 6 deaf students between 14 and 25 years old. Activities of programming directed to the geometry and education in the traffic were carried out. For validation process, data collection instruments were used, which resulted in the emergence of the categories of pedagogical evaluation. It was concluded that these softwares allied to the computational glossary provided the development of logical reasoning that would be hampered by the language barrier.
\end{abstract}

Keywords: computational glossary, cognition, SuperLOGO, Lego Mindstorms NXT, deaf.

Resumo. Esse trabalho tem como objetivo a elaboração de um glossário computacional de sinais com as principais palavras reservadas dos softwares SuperLOGO e Lego Mindstorms NXT como estímulo ao raciocínio lógico em surdos. O trabalho ocorreu em uma Escola Bilíngue de Ensino Médio com 6 alunos surdos entre 14 e 25 anos. Realizou-se atividades de programação direcionadas à geometria e educação no trânsito. Para validação foram utilizados instrumentos de coleta de dados, que resultou no surgimento das categorias de avaliação pedagógica. Concluiu-se esses softwares aliados ao glossário computacional proporcionou desenvolvimento de raciocínio lógico que seriam dificultados pela barreira linguística.

Palavras-chave: glossário computacional, cognição, SuperLOGO, Lego Mindstorms NXT, surdos.

\section{Introdução}

O surdos iniciaram as suas interações com a educação após o reconhecimento da Língua Brasileira de Sinais (LIBRAS) como segunda língua oficial brasileira por meio da Lei 10.436 [Brasil 2002]. O Decreto-Lei 5.626 [Brasil 2005] garante acesso dos alunos surdos à escola regular, com a inclusão desta língua como disciplina curricular, além da formação de profissionais da educação bilíngue, instrutores surdos e intérpretes de LIBRAS [Pereira 2016]. Outro direito adquirido foi o sancionamento da Lei 13.409 [Brasil 2016] que inclui pessoas com deficiência no sistema de cotas adotado pelas 
VII Congresso Brasileiro de Informática na Educação (CBIE 2018)

Anais do XXIX Simpósio Brasileiro de Informática na Educação (SBIE 2018)

universidades e escolas técnicas federais. Essas conquistas permitiram a ampliação no ingresso dos surdos em cursos de nível técnico e superior [Pereira 2016].

Aos que alcançam os cursos de nível técnico e superior enfrentam o problema das disciplinas que possuem termos complexos, adequados às suas especificidades, sem tradução em lingua de sinais, prejudicando seu aprendizado. A LIBRAS é uma língua em construção e a quantidade de sinais para termos técnicos de algumas profissões é insuficiente [SILVA 2011] e relacionado à área da computação este cenário não é diferente. Motivados a resolver essa problemática, o trabalho tem como objetivo elaborar novos sinais técnicos de computação e estimular o raciocínio lógico em alunos surdos. Sendo assim, os autores buscam contribuir na ampliação bibliográfica sobre o tema relacionado a glossários computacionais e propiciar conhecimentos e possibilidades de aprendizado sobre o estímulo de lógica de programação em alunos surdos, que poderá cooperar em pesquisas futuras sobre essa temática.

\section{Trabalhos Relacionados}

Um estudo sobre glossários de termos técnicos de computação em línguas de sinais, disponíveis na internet foi realizado. Dentre os inúmeros glossários pesquisados, serão evidenciados os mais relevantes. Dentre eles, destaca-se o ASL-STEM Forum ${ }^{1}$, um glossário americano colaborativo o qual estudantes surdos, professores, intérpretes, pesquisadores e outros interessados podem consultar, debater e fazer upload de novos sinais, contribuindo para o enriquecimento de termos técnicos da língua $\mathrm{ASL}^{2}$ [Cavender 2010]. Possui um amplo acervo de termos técnicos divididos por áreas de conhecimento, inclusive de computação. A Figura 1 mostra a seção de termos de computação do ASL STEM Forum.

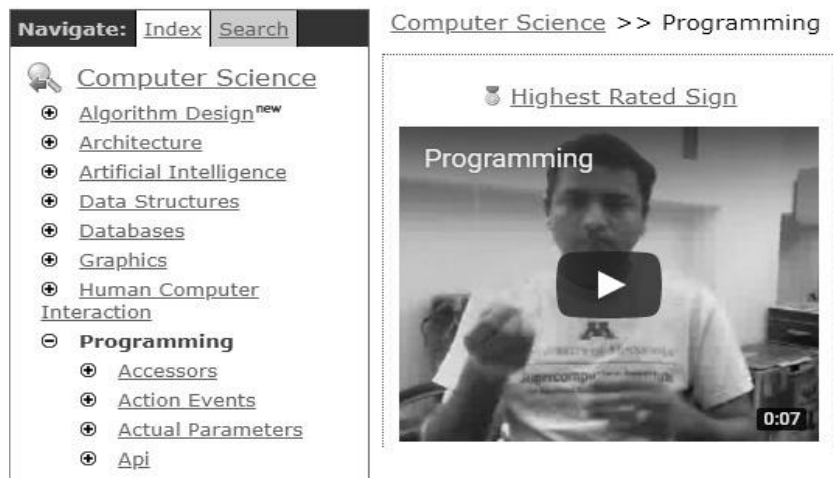

Figura 1. ASL-STEM FORUM

O glossário LIBRAS da UFSC [2018] é um glossário brasileiro de destaque, pois disponibiliza os sinais de termos técnicos de uma forma diferenciada. Ele apresenta o vídeo do sinal, da definição, variações e possíveis exemplos. Possui imagens da configuração dos mãos, localização e disponibiliza o sinal em signwriting, sistema de escrita das linguas gestuais. A Figura 2 apresenta dois vídeos, o sinal da palavra Banco de Dados à esquerda e sua descrição à direita.

\footnotetext{
${ }^{1}$ O ASL STEM Forum pode acessado pela URL: https://aslstem.cs.washington.edu

${ }^{2}$ ASL (American Sign Language) é a lingua de sinais utilizada no Estados Unidos.
} 
VII Congresso Brasileiro de Informática na Educação (CBIE 2018)

Anais do XXIX Simpósio Brasileiro de Informática na Educação (SBIE 2018)

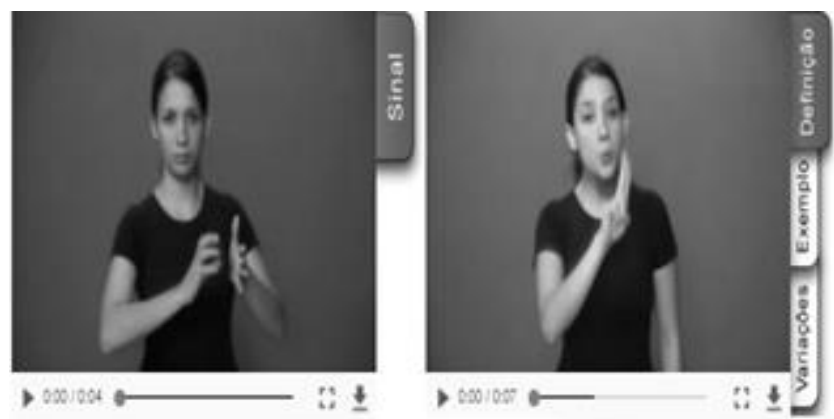

Figura 2. Glossário LIBRAS da UFSC

Além dos glossários apresentados, outros são considerados relevantes nessa pesquisa, tais como, o Spread the Sign ${ }^{3}$ e o VLibras ${ }^{4}$.

\section{Metodologia}

O estudo realizado sobre os glossários de sinais apresentados na seção anterior evidenciaram a necessidade de elaborar um glossário de termos técnicos em LIBRAS na área da computação. Sendo assim, a construção do glossário baseou-se nas ideias de [Vygotsky 2007], que trabalhou com defectologia e ressaltava a utilização de signos e símbolos para o desenvolvimento cognitivo do indivíduo. Para tanto, foi necessária a realização de 4 etapas.

$1^{\text {a) }}$ Pesquisar um software na literatura, que abordasse a lógica de programação e pudesse ser adequado ao público surdo. Nessa etapa, o autor contou com a ajuda do colaborador do projeto, um professor surdo profundo ${ }^{5}$ e bilíngue. Foram pesquisados diversos ambientes de programação tais como Alice e o Scratch, no entanto, na tentativa de aproveitamento de experiências do colaborador surdo, optou-se pelo SuperLOGO. A Figura 3 demonstra a interface do software escolhido.

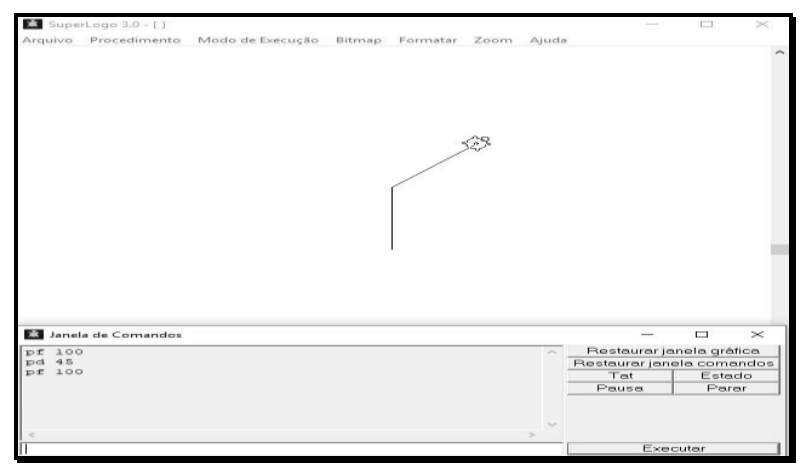

Figura 3. Interface do SuperLOGO

$2^{\mathrm{a}}$ ) Escolher as palavras reservadas do ambiente SuperLOGO para incorporar ao glossário. O critério utilizado na seleção das palavras possibilitou a introdução de conceitos de programação e geometria para iniciantes.

\footnotetext{
${ }^{3}$ O glossário Spread the Sign pode acessado pela URL: http://spreadthesign.com/br

${ }^{4} \mathrm{O}$ site do Vlibras pode ser acessado pela URL: http://www.vlibras.gov.br

${ }^{5}$ Surdo profundo é o indivíduo que apresenta perda auditiva acima de 91 decibéis, ou seja, praticamente não escuta sons.
} 
VII Congresso Brasileiro de Informática na Educação (CBIE 2018)

Anais do XXIX Simpósio Brasileiro de Informática na Educação (SBIE 2018)

$\left.3^{a}\right)$ Elaborar os sinais para o glossário. Esse processo de elaboração não pode ser executado arbitrariamente, os sinais possuem uma sequência específica de gestos, visando facilitar e objetivar o entendimento da informação por parte do público surdo [Granada 2017]. Para elaborar cada sinal, foi levado em consideração a configuração das mãos, ponto de articulação, movimento, disposição e orientação dos gestos e região de contato conforme [Silva 2011].

$4^{\text {a) }}$ Construir a interface do glossário. Desenvolveu-se uma interface acessível e intuitiva, adaptada à realidade do surdo, pois nesses indivíduos, a comunicação se estabelece por meio visual ao contrário dos ouvintes que é concebida via oral e auditiva [Pereira 2016]. Como forma de propagação do glossário computacional, ele está disponivel via $w e b^{6}$. A Figura 4 apresenta a sua interface:

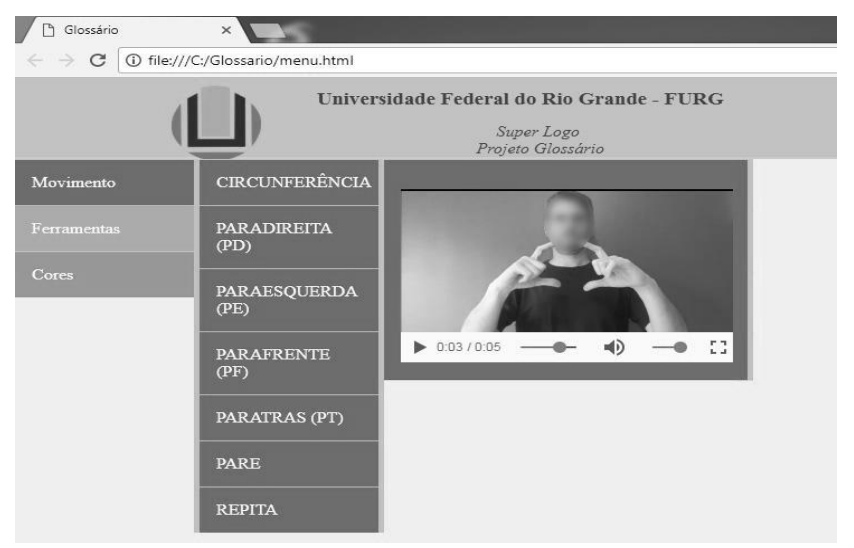

Figura 4. Interface do Glossário

No entanto, O processo de construção do glossário é apresentado na Figura 5.

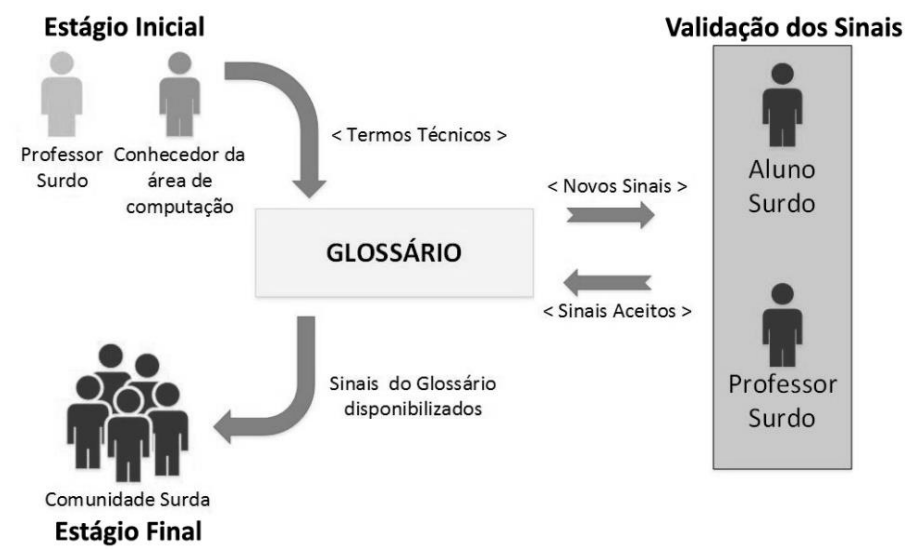

Figura 5. Processo de construção do Glossário

Na Figura 5, o estágio inicial demonstra as quatro etapas descritas na construção do glossário, sendo assim, surge uma nova etapa, a de validação. Para a aprovação dos sinais, é necessária a aceitação por sujeitos surdos ou por especialistas em LIBRAS [Aragão 2015]. Após esse processo, o glossário foi disponibilizado, correspondendo ao estágio final. A etapa de validação será apresentada na sequência.

\footnotetext{
${ }^{6} \mathrm{O}$ glossário computacional pode ser acessado pela URL: http://200.132.77.56:3380/Glossario/Glossario.html
} 
VII Congresso Brasileiro de Informática na Educação (CBIE 2018)

Anais do XXIX Simpósio Brasileiro de Informática na Educação (SBIE 2018)

\subsection{Validação do Glossário}

A validação do glossário realizou-se em uma escola bilíngue de ensino médio, o qual participaram do experimento, uma intérprete de LIBRAS, responsável pela prévalidação dos sinais do glossário, que também atua como diretora da escola, o professor de matemática e seis alunos, entre 14 e 25 anos. Os sujeitos da pesquisa tiveram a identidade preservada, sendo citados apenas por números:

- Sujeito 1 - 14 anos: Comunicativo, esperto, confiante e disciplinado;

- Sujeito 2 - 15 anos: Introvertido, concentrado, inteligente e observador;

- Sujeito 3 - 14 anos: Dedicado e inteligente, porém agitado, tem dificuldade de concentração e insegurança em suas capacidades;

- Sujeito 4 - 15 anos: Tímido que pouco interage com os demais, organizado, atencioso e questionador;

- Sujeito 5 - 22 anos: Deficiente intelectual leve. Dedicado, comunicativo e organizado;

- Sujeito 6 - 25 anos: Deficiente intelectual leve e com baixa visão. Simpático, alegre e observador.

O experimento foi realizado pelo autor juntamente com um bolsista de graduação do grupo InfoEduc, semanalmente totalizando 11 encontros de $1 \mathrm{~h}: 30 \mathrm{~m}$. de duração. $\mathrm{O}$ autor era responsável por ministrar as aulas enquanto que um bolsista da área das ciências humanas tinha a função de documentar e observar o que acontecia na sala de aula, dando suporte pedagógico ao experimento. Sendo assim, os encontros ocorreram na disciplina de matemática com a presença do professor, que também atuava como intérprete.

\subsection{Experimento com o SuperLOGO}

O SuperLOGO é um ambiente de programação de fácil uso e flexível, desenvolvido para estimular o uso da geometria. No primeiro encontro apresentou-se os commandos básicos desse software, que permite a movimentaçao da tartaruga (cursor) pela interface do computador. Junto a isso o glossário computacional de termos técnicos serviu para a consulta dos respectivos sinais e da grafia de cada comando. Instruímos os sujeitos que o glossário deveria ser utilizado em conjunto com o SuperLOGO.

$\mathrm{Na}$ sequência, sugeriu-se uma nova atividade, a construção de um polígono irregular fechado para exercitar o conceito de ângulos e facilitar a compreensão do conteúdo de geometria. Com isso, foi concluída a utilização dos comandos básicos e apresentado o comando "repita", estrutura de repetição que permite executar os mesmos comandos diversas vezes, função utilizada em linguagens de programação. O próximo tópico abordado consistia na utilização do comando "aprenda". Tal funcionalidade permite que o usuário defina novos métodos (comandos) no SuperLOGO por meio de um editor de procedimentos, possibilitando atalhos para construção de determinadas figuras.

\subsection{Experimento com o Lego Mindstorms NXT}

A segunda parte do projeto consistiu em aprimorar as capacidades de raciocínio lógico e, assim, utilizou-se o Lego Mindstorms NXT. Seu uso proporciona o desenvolvimento da lógica, curiosidade e construção do raciocínio especial [Ely 2015]. 
VII Congresso Brasileiro de Informática na Educação (CBIE 2018)

Anais do XXIX Simpósio Brasileiro de Informática na Educação (SBIE 2018)

O principal motivo da utilização do Lego NXT nessa pesquisa, é a possibilidade de projetar de forma concreta, os conceitos abstratos da programação, facilitando o entendimento dos alunos surdos.

Para essa etapa do projeto foi necessário a elaboração de novos sinais para os termos técnicos do Lego Mindstorms NXT porque ele utiliza uma sintaxe mais estruturada que o SuperLOGO, além de usar alguns comandos diferentes. A nova versão teve uma mudança significativa, cada termo técnico possui dois vídeos, o primeiro deles é o sinal propriamente dito e o segundo é a sua descrição. Esse formato é o mesmo utilizado pelo glossário de LIBRAS da UFSC [2018]. Com a adição dos termos técnicos do Lego Mindstorms NXT, o glossário apresenta um total de 52 sinais. A Figura 6 apresenta sua nova versão.

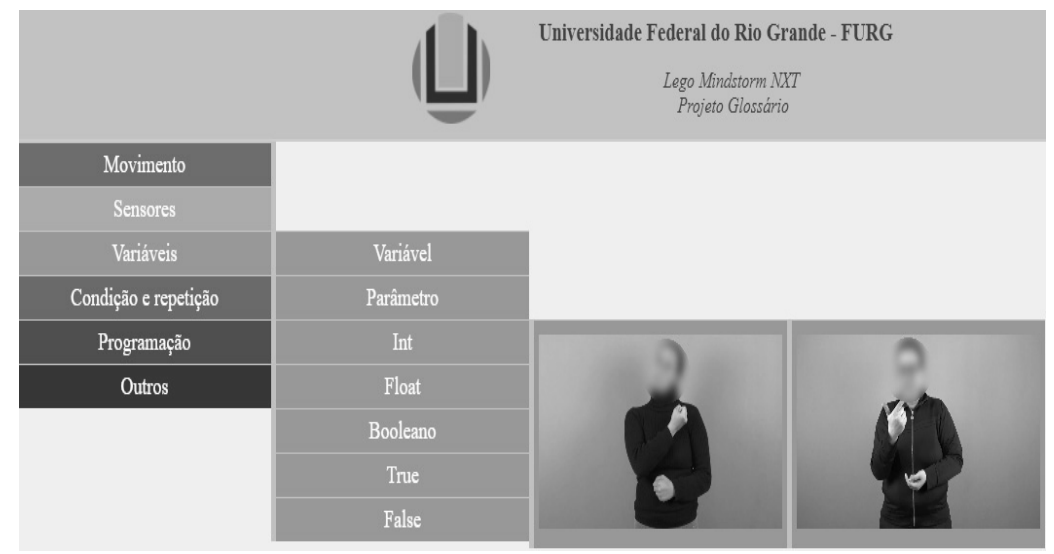

Figura 6. Glossário com termos técnicos do Lego NXT

As atividades com o Lego Mindstorms NXT ocorreram na escola do experimento anterior, porém, com a ausência dos sujeitos 5 e 6 . Nessas atividades foi utilizado um método de trabalho distinto, mencionado por [Deus 2013], que considera 4 princípios para ensino de alunos com surdez, apresentados a seguir:

- Favorecer a atividade dos alunos;

- Organizar as tarefas em pequenos grupos;

- Usar procedimentos visuais de comunicação;

- Proporcionar aos alunos diversas tarefas.

Realizou-se a apresentação do NXT, onde foram exibidos os comandos básicos para movimentação do robô que tinha o forma de um veículo com esteiras. O autor expôs aos sujeitos como o NXT realiza as curvas, processo que exige a percepção de qual das duas esteiras do robô, devem ser ligadas ou desligadas e a quantidade de tempo necessária a ser parametrizada nos comandos para realizar essa ação. Nas tarefas seguintes, os sujeitos programavam os robôs para percorrerem em circuitos prédefinidos, no qual eram explorados os conceitos de geometria, variáveis, sensores, estruturas de condição e procedimentos de aceleração e desaceleração dos robôs.

Para verificar se os sujeitos construíram conhecimentos sobre os conteúdos abordados no Lego Mindstorms NXT, foi proposta uma atividade multidisciplinar sobre educação no trânsito. Assim, elaborou-se um circuito o qual os sujeitos deveriam sair do ponto 1 e escolher a melhor rota para os estacionamentos representados pelos pontos $2 \mathrm{e}$ 3. No trajeto, deveriam respeitar o sentido das ruas, as placas de sinalização, desviando 
VII Congresso Brasileiro de Informática na Educação (CBIE 2018)

Anais do XXIX Simpósio Brasileiro de Informática na Educação (SBIE 2018)

de buracos e não invadindo o gramado e os prédios. Dessa maneira, era necessário construir o circuito no mundo real. Dessa forma, o autor reproduziu a ideia por meio de fitas adesivas e desenhos impressos aplicando-os no piso de um laboratório de computação. A Figura 7 apresenta a ilustração do circuito à esquerda enquanto no lado direito, o circuito físico.

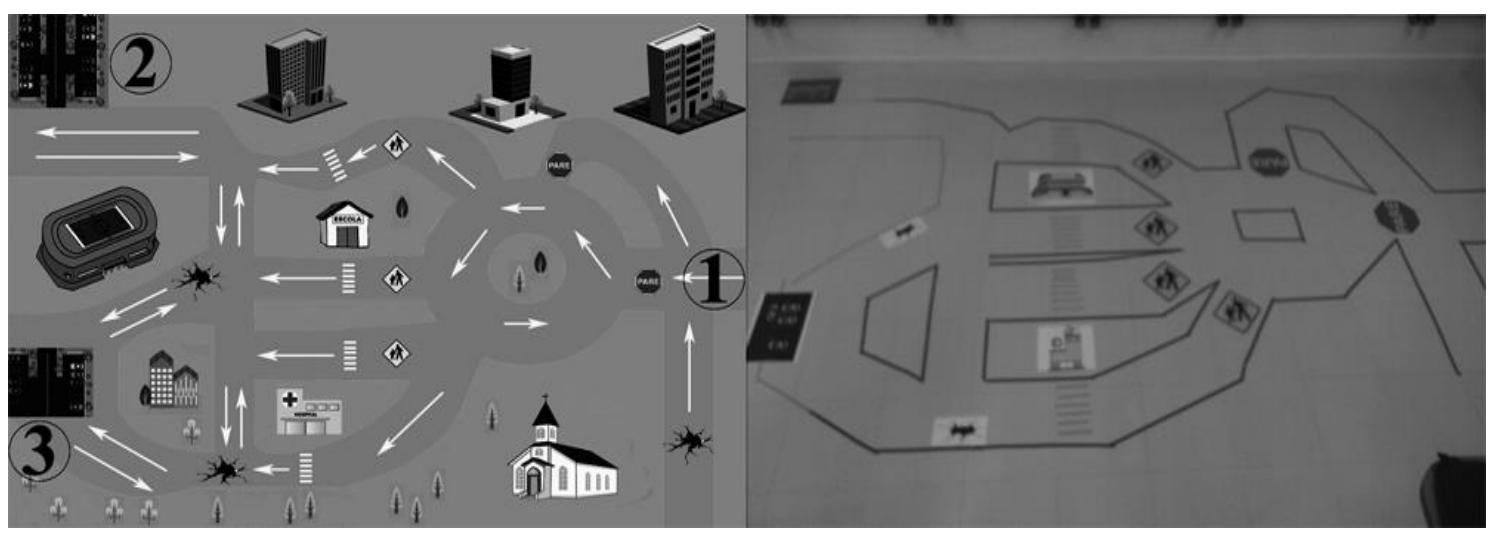

Figura 7. Duas formas de representação do circuito

\section{ANÁLISE E DISCUSSÃO DOS RESULTADOS}

A avaliação pedagógica baseou-se na análise de conteúdo [Bardin 2006] que define um aglomerado de instrumentos metodológicos empregados em discursos variados, ou seja, é uma técnica de pesquisa que interpreta o pensamento do sujeito por meio de conteúdo expressos em textos [Caregnato 2006]. Para a obtenção de dados, utilizou-se a observação direta intensiva, conforme Lakatos [1992] é um tipo de estudo que utiliza os sentidos (ver e ouvir) na obtenção de certos aspectos da realidade. Além disso, utilizou-se questionários e entrevista como instrumentos de avaliação.

Conduziu-se a análise dos dados da seguinte maneira: organização e digitalização das informações documentadas em sala de aula, transcrição da entrevista com o professor de matemática, leitura integral das respostas dos questionários. Além dessas atividades, para definir as categorias de avaliação, gerou-se um mapa mental dos relatórios de aula no formato digital com o minerador de texto Sobek Mining. ${ }^{7}$ Com a sistemática apresentada, emergiu 4 categorias de avaliação, sendo elas, conhecimento, compreensão, atenção e interação. As duas primeiras possibilitaram analisar o aprendizado dos alunos, já a categoria "atenção" permitiu avaliar o grau de interesse e curiosidade, enquanto que a "interação" propiciou a análise da comunicação e o relacionamento entre os sujeitos.

\subsection{Avaliação Pedagógica do Experimento com o SuperLOGO}

Nessa subseção são apresentadas as incidências das categorias em relação aos sujeitos durante os 11 encontros do experimento, indicando a frequência que elas apareceram nas atividades. Os sujeitos 1 e 2 apresentaram os maiores valores na categoria pois demonstraram construção de conhecimento ao desempenhar as tarefas e o uso do glossário, bem como uso contínuo de comandos que exigem raciocínio lógico

\footnotetext{
${ }^{7}$ Para mais informações sobre o Sobek Mining, acesse a URL: http://sobek.ufrgs.br/
} 
VII Congresso Brasileiro de Informática na Educação (CBIE 2018)

Anais do XXIX Simpósio Brasileiro de Informática na Educação (SBIE 2018)

como "repita" e "aprenda". Ambos sujeitos obtiveram o mesmo valor também para a categoria compreensão pois procuravam entender o que havia sido dado na aula, sendo questionadores e com necessidade de aprender. Os sujeitos 3 e 4 apresentaram valores parecidos em quase todos as categorias. Construíram conhecimento sobre os conteúdos abordados, porém eram dispersas e seus desenhos não tinham nenhum planejamento, além de apresentarem algumas dificuldades nos comandos repita e aprenda, o que caracterizou a quantidade de incidências na categoria compreensão. $O$ sujeito 4, pelo fato de ser tímido apresentou índice com valor razoável na categoria interação porque se comunicava esporadicamente com os sujeitos 1 e 3.

Por fim, os sujeitos 5 e 6 tiveram dúvidas em todos os aspectos, não conseguiram desenvolver nenhuma das atividades sem auxílio, demostraram dificuldade ao elaborar os desenhos e entender os conteúdos abordados. Fato que pode ser explicado pela incidência de multideficiências em ambos os sujeitos, segundo Nunes [2008], tais limitações são ocasionadas pelo nível restrito de algumas funções mentais e severos problemas na comunicação. No entanto, obtiveram um nível alto de incidências na categoria interação porque comunicavam-se frequentemente entre si, inclusive em tarefas individuais, em auxílio mútuo. De uma forma geral, todos os sujeitos apresentaram em várias situações, se esforçavam em projetar mentalmente o que deveria ser realizado no computador, para que o desenho fosse concretizado, pois apresentam problemas de abstração. De acordo com Vygotsky [2001], a linguagem se divide em gestual, verbal e escrita e como o surdo não apresenta a linguagem oral, isso pode acarretar dificuldades no seu desenvolvimento e aprendizagem, pois seu pensamento baseia-se em experiências concretas. A figura 8 apresenta as incidências das categorias durante os 11 encontros do experimento, indicando a frequência que elas apareceram nas atividades.

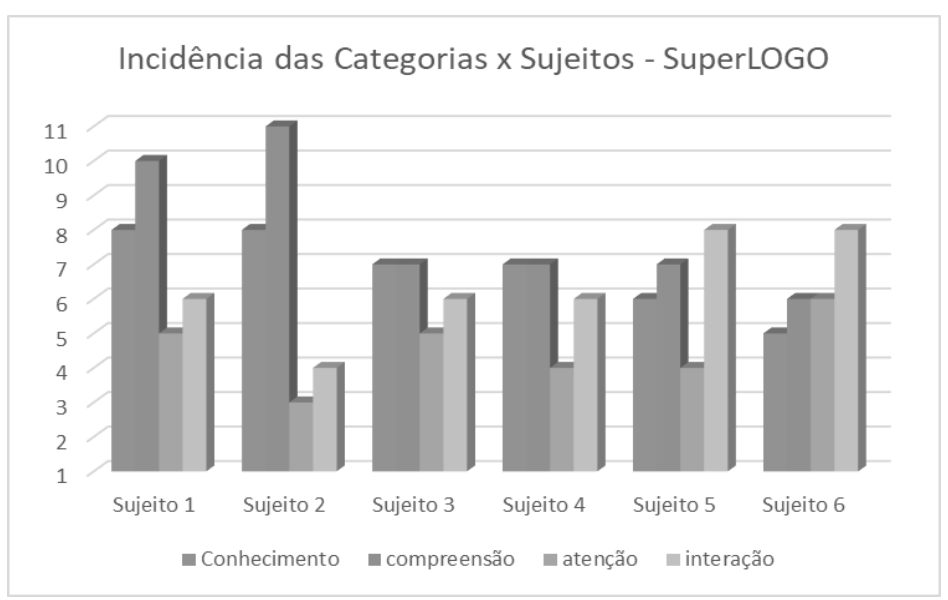

Figura 8. Incidência das categorias no experimento SuperLOGO

\subsection{Avaliação Pedagógica do Experimento com o Lego Mindstorms NXT}

Nessa subseção são apresentadas as incidências das categorias durante os 12 encontros do experimento com o Lego Mindstorms NXT. Na categoria conhecimento, os sujeitos 1 e 2 apresentaram um alto índice de incidências porque desenvolveram as atividades corretamente em praticamente todos os conteúdos abordados. No entanto, na categoria compreensão, esses sujeitos apresentaram o mesmo valor de incidências pois evidenciaram assimilação nos conteúdos abordados e dificuldades semelhantes. $\mathrm{Na}$ 
VII Congresso Brasileiro de Informática na Educação (CBIE 2018)

Anais do XXIX Simpósio Brasileiro de Informática na Educação (SBIE 2018)

categoria atenção, o grupo apresentou baixo nível de incidências porque exibiu diferentes comportamentos. Os sujeitos 2 e 3 se mostraram concentrados em todas as atividades enquanto que os sujeitos 1 e 4, se revelaram dispersos. Na categoria interação, os sujeitos obtiveram um valor alto porque se comunicavam frequentemente entre si, com o autor e intérprete, seja nas atividades de fixação ou nas discussões sobre os conteúdos. A figura 9 apresenta as incidências das categorias em relação aos sujeitos durante os encontros do experimento, indicando a frequência que apareceram nas atividades.

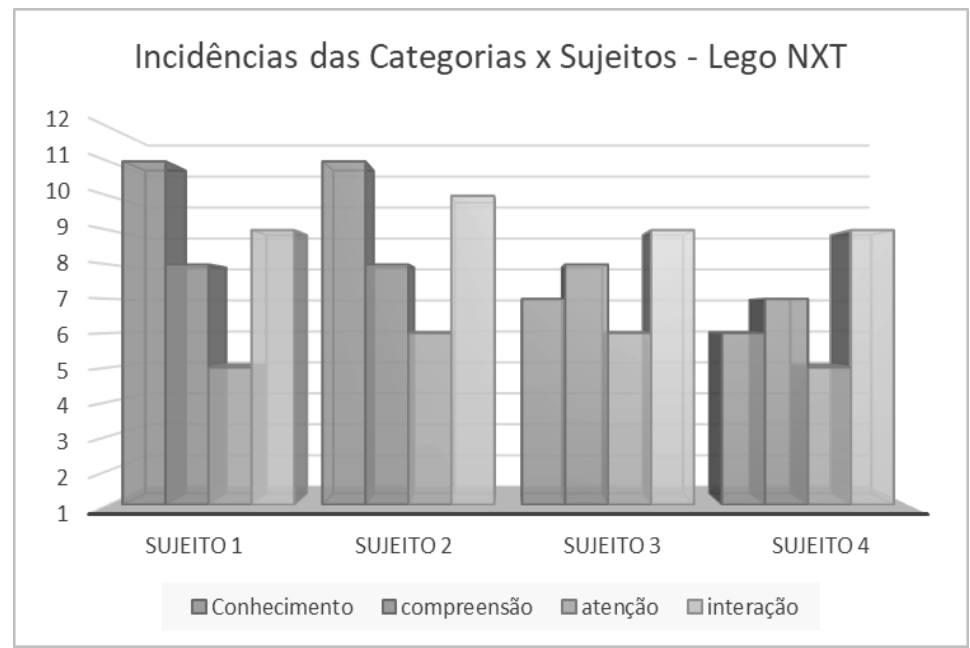

Figura 9. Incidência das categorias no experimento com Lego NXT

Os sujeitos apresentaram dificuldades na compreensão de variáveis pois nelas ocorre alteração de valores e os sujeitos não conseguiam assimilar essa variação. Isso pode ocorrer porque os surdos são indivíduos que durante sua infância sofreram atrasos no progresso de suas habilidades metacognitivas, ou seja, a sua capacidade de entender a informação que lhe é demonstrada e na sua assimilação [Bisol 2010]. Por outro lado, demonstraram construção de conhecimento ao realizarem as tarefas propostas, principalmente, na atividade sobre educação de trânsito, o qual programaram o robô NXT em um circuito elaborado e com várias regras.

\section{Considerações Finais}

Este artigo apresentou de que maneira ocorreram os experimentos para estimular a lógica de programação em alunos surdos por meio de um glossário com termos técnicos de computação em LIBRAS. Foram apresentados alguns trabalhos relacionados ao tema, que evidenciaram a necessidade da elaboração dos sinais e construção do glossário. O uso desse recurso com palavras reservadas do SuperLOGO e Lego NXT propiciou aos sujeitos a construção de conhecimento sobre os conceitos básicos de programação e geometria. Como forma de avaliação dos sujeitos foram estabelecidas 4 categorias que possibilitaram a análise de comportamento nas atividades para desenvolvimento de raciocínio lógico. Nela, foram realçados suas habilidades, restrições e dificuldades. Apesar dos sujeitos avaliados constituírem um grupo heterogêneo, com autonomia, construíram sua aprendizagem de forma individual e coletiva por meio das atividades apresentadas. Essa pesquisa pode oportunizar aos surdos acesso a cursos de computação e com perspectivas de frequentar um curso de ensino superior nessa área. 
VII Congresso Brasileiro de Informática na Educação (CBIE 2018)

Anais do XXIX Simpósio Brasileiro de Informática na Educação (SBIE 2018)

\section{Referências}

J. Aragão et al (2015) "Um estudo da validade de conteúdo de sinais, sintomas e doenças/agravos em saúde expressos em LIBRAS". Revista Latino-Americana de Enfermagem, v. 23, n. 6, p. 1014-1023.

Bardin L. (2006), Análise do discurso, Lisboa Edições, v. 70.

BRASIL. (2002) "Lei 10.436, de 24 de abril de 2002", http://www.planalto.gov.br/ccivil_03/leis/2002/L10436.htm, Abril.

BRASIL. (2005) "Decreto 5.626, de 22 de dezembro de 2005", http://www.planalto.gov.br/ccivil_03/_ato2004-2006/2005/decreto/d5626.htm, Dezembro.

BRASIL. (2016) "Lei $\mathrm{n}^{\mathrm{o}}$ 13.409, de 28 de dezembro de 2016", http://www.planalto.gov.br/ccivil_03/_ato2015-2018/2016/lei/L13409.htm, Abril.

C. Bisol and T. Sperb. (2010) "Discursos sobre a surdez: deficiência, diferença, singularidade e construção de sentido", Psicologia: Teoria e Pesquisa, v. 26, n. 1.

C. Cavender et al. (2010) "Asl-stem forum: enabling sign language to grow through online collaboration.", In: Proceedings of the SIGCHI Conference on Human Factors in Computing Systems. ACM. p. 2075-2078.

M. Deus. (2013) "Surdez: linguagem, comunicação e aprendizagem do aluno com surdez na sala de aula comum", Revista Anápolis Digital. Vol.3, n.1.

I. Ely and D. Almeida. (2015) "Robótica pedagógica criativa: um aprendizado itinerante", Revista Extensão em Foco, v. 3 n. 1, p. 7-19.

Lakatos E. and Marconi M. (1992), Metodologia do trabalho científico. São Paulo: Atlas. $4^{\mathrm{a}} \mathrm{ed}$.

C. Nunes. (2008) "Alunos com multideficiência e com surdocegueira congênita", Direção de Serviços da Educação Especial e do Apoio Sócio-Educativo. Lisboa.

D. Pereira, and E. Silva. (2016) "Teclibras: Um Protótipo Web de apresentação de Termos de Informática em Libras", Revista Fórum, n. 33.

R. Caregnato and R. Mutti. (2006) "Pesquisa qualitativa: análise de discurso versus análise de conteúdo", Texto contexto enferm, v. 15, n. 4, p. 679-684.

R. Granada et al. (2017) "Dicionário de termos de computação como facilitador no ensino de programação para surdos. In: Anais do III Workshop de Ensino em Pensamento Computacional, Algoritmos e Programação (Walgprog) - VI CBIE, Recife, Pernambuco, Brasil.

I. Silva and B. Santana. (2011) "Libras e Ensino Técnico: A necessidade de novos sinais”, VII Jornada de Iniciação Científica - PIVIC Mackenzie/Mack Pesquisa.

UFSC. (2018) “Glossário Letras Libras”, http://glossario.libras.ufsc.br, Maio.

Vygotsky, L. (2001), A Construção do Pensamento e Linguagem. Martins Fontes. $1^{\text {a }}$ Ed.

Vygotsky, L. (2007), Formação Social da Mente. Martins Fontes. $7^{\mathrm{a}}$ Ed. 